\title{
Meibomian gland dysfunction and ocular discomfort in video display terminal workers
}

C Fenga', P Aragona², A Cacciola', R Spinella ${ }^{2}$, C Di Nola' ${ }^{1}$, F Ferreri ${ }^{2}$ and L Rania ${ }^{2}$

\section{Abstract \\ Purpose Meibomian gland dysfunction} (MGD) is one of the most common ocular disorders encountered in clinical practice. The clinical manifestations of MGD are related to the changes in the tear film and ocular surface with symptoms of ocular discomfort. In recent years, many surveys have evaluated symptoms associated with the use of Video Display Terminals (VDT), and VDT use is recognized as a risk factor for eye discomfort.

The aim of the present study was to determine if the presence of MGD contributes to the signs and symptoms of ocular discomfort during the use of VDT.

Methods In course of a routine health surveillance programme, a group of 70 subjects fulfilled the inclusion criteria and responded to a questionnaire about symptoms of ocular discomfort. The following ocular tests were performed: tear break-up time, fluorescein corneal stain, and basal tear secretion test. Results A total of $\mathbf{5 2}$ subjects out of $\mathbf{7 0}$ (74.3\%) had MGD. A statistically significant correlation between the symptoms of ocular discomfort and hours spent on VDT work was observed in the total population $(r=0.358$; $P=0.002 ; 95 \%$ CI $0.13-0.54)$ and in the group of subjects with MGD $(r=0.365 ; P=0.009 ; 95 \%$ CI 0.103-0.58). Such correlation was not shown in subjects without MGD.

Conclusions The high prevalence of MGD among the subjects with symptoms of ocular discomfort suggests that this diagnosis should be considered when occupational health practitioners encounter ocular complaints among VDT operators. It appears that MGD can contribute to the development of ocular discomfort in VDT operators. Eye (2008) 22, 91-95; doi:10.1038/sj.eye.6703025; published online 26 October 2007
Keywords: Meibomian gland dysfunction; video display terminal; ocular surface; conjunctiva; cornea; tear film

\section{Introduction}

The Meibomian glands are responsible for the secretion of tear lipids that play an important role in the tear film stability, lubrication of the ocular surface and formation of a clear optical image. ${ }^{1}$ Dysfunction of the Meibomian glands (MGD) is accompanied by hyperaemia and thickening of the lid margins, thickened lipid secretion and keratinisation of gland ducts, with consequent reduced lipid secretion into the tear film. $^{2}$

MGD is believed to be one of the major causes of ocular discomfort and abnormalities of the ocular surface. ${ }^{3}$ It has also been demonstrated that in people working long hours at video display terminals (VDT), ocular discomfort is often present. ${ }^{4}$ This finding is supported by several surveys which suggest that VDT users frequently suffer from work-related symptoms of ocular discomfort and show ocular surface signs such as corneal abnormalities or instability of the precorneal tear film. ${ }^{5-8}$

Although much has been written about both MGD and ocular discomfort associated with VDT use, there are no published data about the relationship between MGD and such ocular symptoms arising in the course of VDT use.

The aim of the present study was to evaluate if MGD could contribute to the development of signs and symptoms of ocular discomfort related to the use of VDT.

\section{Materials and methods}

The study was carried out at the Section of Occupational Health, Department of Social and
${ }^{1}$ Department of Social and Environmental Health-Section of Occupational Health, University of Messina, Messina, Italy

${ }^{2}$ Department of Surgical Specialties - Section of Ophthalmology, University of Messina, Messina, Italy

Correspondence:

P Aragona,

Department of Surgical

Specialties, Section of Ophthalmology,

Policlinico Universitario, Via Consolare Valeria Gazzi, Messina 98125, Italy. Tel: + 390902937 060; Fax: + 390902924819 . E-mail: paragona@ unime.it

Received: 29 July 2007 Accepted in revised form: 2 October 2007 Published online: 26 October 2007 
Environmental Health and at the Ocular Surface Unit, Section of Ophthalmology of the Department of Surgical Specialties of the University of Messina, Italy.

In the course of a routine health surveillance programme carried out on VDT workers, 70 subjects of the 83 screened ( 34 male and 36 female with age ranging from 31 and 56 years, mean $45.4 \pm$ SD 6.8) fulfilled the criteria for inclusion and agreed to participate in the present study.

Inclusion criteria were: living in the Messina metropolitan area, working at a VDT, willing and able to attend for the required study visit, and lack of any systemic disease.

Exclusion criteria were as follows: any systemic disease, post-menopausal status, uncorrected refractive error, glaucoma or ocular hypertension, retinal disorders, use of any ocular medication within one month of the beginning of the study, and systemic treatment with drugs such as $\beta$-blocking agents, benzodiazepines, hormones, antihistamines, and other agents which could interfere with tear production.

A questionnaire was administered to all subjects examined, enquiring about the presence of ocular symptoms such as burning, itching, foreign body sensation, dryness, tearing, photophobia, pain, mucus secretion, redness, and heaviness. Patients were asked to score the intensity of each symptom according to the following scoring system: $0=$ absent, $1=$ mild, $2=$ moderate, $3=$ severe. The scores of each feature were added up to give a total score, indicating the degree of ocular discomfort. This score was used for statistical purposes.

A single specialist in Occupational Medicine (CF) carried out the interviews and administered the questionnaire to all the subjects.

All subjects included in the study provided a written informed consent at the beginning of the study.

\section{Ophthalmologic examination}

The clinical examination, carried out by an ophthalmologist (RS), included visual acuity assessment, tonometry, and fundus examination. For the ocular surface study, the following tests were performed: slit-lamp examination of the ocular surface, tear film break-up time (BUT), corneal fluorescein staining and tear basal secretion. The ophthalmic examination was performed at the end of the work shift.

The slit-lamp examination of the ocular surface was used to study the presence of conjunctival signs such as: erythema, papillae, follicles, and plications. These features were classified according to the following scoring system: $0=$ absent, $1=$ mild, $2=$ moderate, $3=$ severe. The scores of each feature were added up to give a total sum, representative of the objective condition of the conjunctiva.

For the Meibomian gland assessment, the following features were studied: hyperaemia and thickening of the lid margin, presence of a thickened lipid secretion, keratinisation, and consequent functional obstruction of the orifices of the ducts. When more than one-third of the lid structures showed such features the subject was considered positive for MGD.

For BUT, a single drop of unit dose saline (Sodio Cloruro 0.9\%, S.A.L.F. S.p.A. Laboratorio Farmacologico, Cenate Sotto (BG), Italy) was instilled onto a fluoresceinimpregnated strip (Fluorescein paper, Haag Streit AG, Köniz, Swiss). When the drop saturated the impregnated tip, the excess was shaken into a waste bin with a sharp flick. The right lower lid was then pulled down and the strip was tapped onto the lower tarsal conjunctiva. A similar procedure was carried out on the left lower lid. Normal value for the test was considered a tear break-up time above $10 \mathrm{~s} .{ }^{9}$

The patients were then asked to blink for a while in order to allow mixing of the fluorescein on the corneal surface. A stopwatch was started immediately after the last blink. The whole pre-corneal tear film was then checked with the slit-lamp using the cobalt blue filter. The time interval elapsed between last blink and the appearance of a black zone on the corneal surface was registered; the interval was measured three times and the mean result was recorded.

The corneal fluorescein stain evaluation was performed three minutes after the BUT. The presence of any fluorescein staining of the corneal epithelial surface was scored from 0 to 3 considering five corneal areas as described by Lemp. ${ }^{9}$

A tear basal secretion test was carried out. The instillation of anaesthetic, $0.4 \%$ Oxybuprocain eyedrops (Novesina ${ }^{\circledR}$, Novartis Pharma S.p.A., Origgio (VA), Italy) was performed on the conjunctival cul-de-sac and lid margin in order to achieve a good anaesthesia of the ocular surface. The instillation was repeated twice with 2 min of interval between each instillation. The anaesthetic was not removed and the strips were placed when the subjects reported of not feeling anymore the wet sensation that follows the instillation of the drug. In this way, any procedure of the removal of the anaesthetic that may irritate the ocular surface and give a reflex tearing was avoided and it was possible to measure the tear production without any stimulus due to the contact of the Schirmer's strip with the lid margin and the conjunctival sac. A strip of dry filter paper (Schirmer tear test, Clement Clarke International Ltd., Harlow, Essex, UK) was placed in the lower fornix at the junction of lateral and middle third, taking care to avoid touching the cornea. ${ }^{10}$ The subject was seated on a chair with a 
head rest, in a room with dim illumination and was asked to blink normally. The strip was removed after $5 \mathrm{~min}$, and the wetted length of the filter paper was measured. A wetting lower than $5 \mathrm{~mm} / 5^{\prime}$ was considered abnormal. ${ }^{11}$

\section{Statistical analysis}

Spearman's and Pearson's correlation coefficients were calculated, as appropriate, for the evaluation of the correlation between daily working hours at VDT and the intensity of symptoms score and tests results, respectively.

Fisher's exact test was performed to compare the ocular discomfort symptoms prevalence between VDT workers with or without MGD.

Mann-Whitney $U$-test was used for statistical analysis of symptom score differences between groups 1 and 2 . Only the results from the right eye were taken into account for statistical purposes.

We certify that all applicable institutional and governmental regulations concerning the ethical use of human volunteers were followed during this research.

\section{Results}

Among 70 subjects, who fulfilled the inclusion criteria and agreed to participate in the study, $62(88.6 \%)$ had ocular discomfort symptoms, while 52 out of $70(74.3 \%)$ showed the presence of MGD at clinical assessment. According to the presence or absence of MGD, the population was divided into two groups: group 1, including 52 subjects with MGD (26 M, 26 F, aged $45.9 \pm 6.3)$ and group 2, including 18 subjects without MGD (8 M, $10 \mathrm{~F}$, aged $44 \pm 8$ ).

In Table 1, the descriptive statistics of the whole group and of the two groups obtained dividing the subjects according to the presence or absence of MGD, are summarized.
When the subjects were considered according to the presence or absence of MGD a similar prevalence of ocular discomfort symptoms (group $1=80.8 \%$; group $2=88.9 \% ; P=0.34)$ and symptom score $(P=0.31)$ was observed in the two groups.

Considering, in the whole group, the correlation between daily hours spent at VDT with ocular test results and symptoms score respectively, it was shown a statistically significant correlation only between daily hours spent at VDT and symptoms score $(r=0.358$; $P=0.002 ; 95 \% \mathrm{CI}=0.13-0.54)$. Furthermore, in group 1 , a correlation was found between daily hours spent at VDT and symptom score $(r=0.365 ; P=0.009 ; 95 \% \mathrm{CI}=0.103$ 0.58 ) (Table 2). No correlation was found, in these subjects, between hours spent at VDT and, respectively, BUT and the basal tear secretion test (Table 3).

Subjects without MGD (group 2) showed a statistically significant inverse correlation between daily hours spent at VDT and symptom score $(r=-0.600 ; P=0.01 ; 95 \%$ $\mathrm{CI}=-0.833$ to -0.185 ) (Table 2 ) and a statistically significant correlation between daily hours spent at VDT and tear basal secretion test $(r=0.63 ; P=0.004 ; 95 \%$ $\mathrm{CI}=0.24-0.85$ ) (Table 4).

\section{Discussion}

In the present study, a group of 70 VDT operators was examined to evaluate if MGD could contribute to the

Table 2 Correlation between daily hours spent at VDT work and ocular discomfort symptom score in VDT workers

\begin{tabular}{lccc}
\hline & $\begin{array}{c}\text { Correlation } \\
(\mathrm{r})\end{array}$ & $\begin{array}{c}\text { Significance } \\
(\mathrm{P})\end{array}$ & $95 \% \mathrm{CI}$ \\
\hline $\begin{array}{l}\text { Whole group } \\
(n=70)\end{array}$ & 0.358 & 0.002 & $0.13-0.54$ \\
$\begin{array}{l}\text { Subjects with MGD } \\
(n=52)\end{array}$ & 0.365 & 0.009 & $0.103-0.58$ \\
$\begin{array}{l}\text { Subjects without } \\
\text { MGD ( } n=18)\end{array}$ & -0.600 & 0.01 & -0.833 to -0.185 \\
\hline
\end{tabular}

Table 1 Mean values and SD of the test results in the subjects as a whole and divided according to the presence or absence of MGD

\begin{tabular}{|c|c|c|c|}
\hline & $\begin{array}{l}\text { All subjects } \\
\quad(\mathrm{n}=70)\end{array}$ & $\begin{array}{l}\text { Patients with MGD } \\
\text { group } 1(\mathrm{n}=52)\end{array}$ & $\begin{array}{l}\text { Patients without } \\
\text { MGD group } 2 \\
(\mathrm{n}=18)\end{array}$ \\
\hline VDT use (h/day) & $3.9 \pm 1.7$ & $3.7 \pm 1.6$ & $4.3 \pm 1.9$ \\
\hline Symptoms (score) & $6.5 \pm 5.3$ & $5 \pm 4.6$ & $6.2 \pm 3.7$ \\
\hline Conjunctival signs (score) & $3 \pm 2$ & $3.6 \pm 1.8^{\mathrm{a}}$ & $1 \pm 1.2$ \\
\hline BUT (s) & $3.5 \pm 1.9$ & $3.4 \pm 1.9$ & $3.9 \pm 1.9$ \\
\hline Corneal fluorescein stain (score) & $0.1 \pm 0.3$ & $0.04 \pm 0.2$ & $0.3 \pm 0.5$ \\
\hline Tear basal secretion test $\left(\mathrm{mm} / 5^{\prime}\right)$ & $20.4 \pm 11.1$ & $18.1 \pm 11.2^{\mathrm{b}}$ & $24.5 \pm 7.3$ \\
\hline
\end{tabular}

\footnotetext{
a $P<0.001$ vs group 2.
}

${ }^{\mathrm{b}} \mathrm{P}<0.02$ vs group 2. 
Table 3 Correlation between daily hours spent at VDT work and results of objective tests in subjects with MGD (group 1)

\begin{tabular}{lccc}
\hline $\begin{array}{l}\text { Group 1 } \\
(\mathrm{n}=52)\end{array}$ & Correlation $(\mathrm{r})$ & $\begin{array}{c}\text { Significance } \\
(\mathrm{P})\end{array}$ & $95 \% \mathrm{CI}$ \\
\hline BUT & -0.07 & 0.58 & -0.34 to 0.2 \\
$\begin{array}{l}\text { Fluorescein } \\
\text { score }\end{array}$ & -0.12 & 0.38 & -0.38 to 0.15 \\
$\begin{array}{l}\text { Basal secretion } \\
\text { test }\end{array}$ & -0.21 & 0.12 & -0.46 to 0.06 \\
\hline
\end{tabular}

Table 4 Correlation between daily hours spent at VDT work and results of objective tests in subjects without MGD (group 2)

\begin{tabular}{lccc}
\hline $\begin{array}{l}\text { Group 2 } \\
(\mathrm{n}=18)\end{array}$ & Correlation (r) & $\begin{array}{c}\text { Significance } \\
(\mathrm{P})\end{array}$ & $95 \% \mathrm{CI}$ \\
\hline $\begin{array}{l}\text { BUT } \\
\begin{array}{l}\text { Fluorescein } \\
\text { score }\end{array}\end{array}$ & 0.11 & 0.63 & -0.36 to 0.55 \\
$\begin{array}{l}\text { Basal secretion } \\
\text { test }\end{array}$ & 0.63 & 0.25 & -0.21 to 0.65 \\
\hline
\end{tabular}

presence of ocular discomfort symptoms related to the work at VDT.

The results have shown that subjects with MGD showed a statistically significant higher presence of conjunctival signs and lower tear basal secretion. It was also found that subjects with MGD showed a statistically significant correlation between hours spent at VDT and ocular discomfort symptoms, while in subjects without MGD was observed a statistically significant inverse correlation. Probably, this feature might be related to the higher amount of tear basal secretion in subjects without MGD. In fact, a better tear secretion could contribute to compensate the effects that the use of VDT can induce on the ocular surface. A consequence of this is that people with fewer symptoms tend to work for longer time at VDT.

Among the health problems associated with the use of VDT, eyestrain is the most common, single complaint. Several studies have demonstrated a higher prevalence of ocular discomfort symptoms among VDT operators compared with office workers doing comparable jobs not involving VDT use. ${ }^{12-16}$ To date VDT work is recognised as a high-risk factor for eye discomfort or asthenopia.

Various factors have been shown to be responsible for the onset of ocular complaints among VDT users. These include the type of VDT displays, the time spent on VDT, the workstation ergonomics, the indoor environment, and the type of working practice. ${ }^{17-21}$ The presence of refractive disorders and other ocular conditions such as reduced blinking, reduced BUT, tears abnormalities, and ocular surface alterations ${ }^{22-24}$ were also described as causes of ocular discomfort in VDT operators. ${ }^{15}$
The association between dry eye and symptoms of asthenopia in VDT workers was described by Nakaishi and Yamada, ${ }^{12}$ who found a high prevalence of dry eye (studied with the phenol red thread test, indicating a reduced tear secretion from the lacrimal gland) in VDT operators with asthenopic symptoms. The authors concluded that dry eye could be considered a more common cause of asthenopia than refractive errors in VDT users.

MGD, a widespread, ocular disorder, is responsible for the increased evaporation of the tear film with consequent tear hyperosmolarity, which was shown to be one of the most important factors for the development of ocular discomfort. ${ }^{25,26}$ In addition, the lid changes occurring in course of MGD such as thickening, hyperaemia, and eyelash malposition may contribute to the signs of ocular irritation often occurring in these patients, resulting from irregular lid margin and consequent inefficient tear distribution over the ocular surface. ${ }^{27-29}$ In the present study, a lower tear basal secretion and more evident conjunctival alterations were observed in subjects with MGD; these findings may also contribute to the presence of ocular discomfort symptoms during the work at VDT.

MGD has not previously been reported to correlate with the symptoms of ocular discomfort in VDT workers.

There is evidence supporting the notion that VDT use decreases the blink rate and possibly reduces the stability of the precorneal tear film. ${ }^{6}$

Our finding of a correlation between work at VDT and ocular discomfort symptoms in MGD subjects suggests that this feature should be taken into consideration when occupational health practitioners encounter ocular complaints among VDT operators.

\section{References}

1 Mathers WD, Shield WJ, Sachdev MS, Petroll WM, Jester JV. Meibomian gland dysfunction in chronic blepharitis. Cornea 1991; 10: 277-287.

2 Yokoi N, Mossa F, Tiffany JM, Bron AJ. Assessment of Meibomian gland function in dry eye using meibometry. Arch Ophthalmol 1999; 117: 723-729.

3 Shimazaki J, Sakata M, Tsubota K. Ocular surface changes and discomfort in patients with Meibomian gland dysfunction. Arch Ophthalmol 1995; 113: 1266-1270.

4 Nakazawa T, Okubo Y, Suwazono Y, Kobayashi E, Komine $\mathrm{S}$, Kato $\mathrm{N}$ et al. Association between duration of daily VDT use and subjective symptoms. Am J Ind Med 2002; 42 421-426.

5 Bergqvist UO, Knave BG. Eye discomfort and work with visual display terminals. Scand J Work Environ Health 1994; 20: 27-33.

6 Patel S, Henderson R, Bradley L, Galloway B, Hunter L. Effect of visual display unit use on blink rate and tear stability. Optom Vis Sci 1991; 68: 888-892. 
7 Tsubota K, Nakamori K. Dry eye and video display terminals. N Engl J Med 1993; 328: 584.

8 Franck $C$, Inger B. Break-up time and lissamine green epithelial damage in 'office eye syndrome'. Acta Ophthalmol 1993; 71: 62-64.

9 Lemp MA. Report of the National Eye Institute/Industry workshop on clinical trials in dry eye. CLAO J 1995; 21: 221-232.

10 Aragona P, Cannavó SP, Borgia F, Guarneri F. Utility of studying the ocular surface in patients with acne vulgaris treated with oral isotretinoin: a randomized controlled trial Br J Dermatol 2005; 152: 576-578.

11 Aragona P, Tripodi G, Spinella R, Di Stefano G, Ferreri G. Test lacrimali nella diagnostica della sindrome di Sjögren. Boll Ocul 1998; 77(Suppl 1): 13-17.

12 Nakaishi H, Yamada Y. Abnormal tear dynamics and symptoms of eyestrain in operators of visual display terminals. Occup Environ Med 1999; 56: 6-9.

13 Mocci F, Serra A, Corrias GA. Psychological factors and visual fatigue in working with video display terminals. Occup Environ Med 2001; 58: 267-271.

14 Gobba FM, Broglia A, Sarti R, Luberto F, Cavalleri A. Visual fatigue in video display terminal operators: objective measure and relation to environmental conditions. Int Arch Occup Environ Health 1988; 60: 81-87.

15 Thomson WD. Eye problems and visual display terminals: the facts and the fallacies. Ophthal Physiol Opt 1998; 18: 111-119.

16 Travers PH, Stanton BA. Office workers and video display terminals: physical, psychological and ergonomic factors. AAOHN J 2002; 50: 489-493.

17 Muzi G, Abbritti G, Accattoli MP, dell'Omo M. Prevalence of irritative symptoms in a nonproblem air-conditioned office building. Int Arch Occup Environ Health 1998; 71: 372-378.
18 Fenga C, Aragona P, Cacciola A, Ferreri F, Spatari G, Stilo A et al. Ocular discomfort and conjunctival alterations in operating room workers. A single-institution pilot study. Int Arch Occup Environ Health 2001; 74: 123-128.

19 Mc Donald JC, Armstrong B, Bénard J, Cherry NM, Farant JP. Sick buildings syndrome in a Canadian office complex. Arch Environ Health 1993; 48: 298-304.

20 Satici A, Bitiren M, Ozardali I, Vural H, Kilic A, Guzey M. The effects of chronic smoking on the ocular surface and tear characteristics: a clinical, histological and biochemical study. Acta Ophthalmol Scand 2003; 81: 583-587.

21 Kjaergaard S, Pedersen OF, Molhave L. Sensitivity of the eyes to airborne irritant stimuli: influence of individual characteristics. Arch Environ Health 1992; 47: 45-50.

22 Baudouin C. The pathology of dry eye. Surv Ophthalmol 2001; 45(Suppl 2): S211-S220.

23 Nichols KK, Nichols JJ, Lynn Mitchell G. The relation between tear film tests in patients with dry eye disease. Ophthalmic Physiol Opt 2003; 23: 553-560.

24 Tsubota K. Tear dynamics and dry eye. Prog Retin Eye Res 1998; 17: 565-596.

25 Mathers WD. Ocular evaporation in Meibomian gland dysfunction and dry eye. Ophthalomology 1993; 100: 347-351.

26 Goto E, Shimazaki J, Monden Y, Takano Y, Yagi Y, Shimmura $\mathrm{S}$ et al. Low-concentration homogenized castor oil eye drops for noninflamed obstructive Meibomian gland dysfunction. Ophthalmology 2002; 109: 2030-2035.

27 Craig JP, Singh I, Tomlinson A, Morgan PB, Efron N. The role of tear physiology in ocular surface temperature. Eye 2000; 14: 635-641.

28 Bron AJ, Benjamin L, Snibson GR. Meibomian gland disease. Classification and grading of lid changes. Eye 1991; 5: 395-411.

29 McCulley IP, Shine WE. The lipid layer of tears: dependent on Meibomian gland function. Exp Eye Res 2004; 78: 361-365. 